\title{
KİMYASAL BUHAR BİRİKTİRME YÖNTEMİ İLE GRAFEN SENTEZİNE TAVLAMA VE BÜYÜTME SÜRELERININ ETKİSI
}

\author{
${ }^{1}$ Recep ZAN, ${ }^{2}$ Gülcan UTKU, ${ }^{3}$ Ali ALTUNTEPE \\ 1,2 Niğde Ömer Halisdemir Üniversitesi, Fen Edebiyat Fak., Fizik Bölümü, Niğde \\ 1,3 Niğde Ömer Halisdemir Üniversitesi, Nanoteknoloji Uyg. ve Arş. Merkezi Niğde \\ 1recep.zan@ohu.edu.tr, 2gcan_yil@hotmail.com, 3altuntepeali@hotmail.com
}

(Geliş/Received: 17.09.2018; Kabul/Accepted in Revised Form: 09.12.2018)

ÖZ: Son yılların en ilgi çekici malzemelerinden biri olan grafen yüksek iletkenlik, yüksek dayanım ve saydamlık gibi birçok üstün özelliğe sahiptir. Grafenin kimyasal buhar biriktirme tekniği kullanılarak sentezlenmesinde, büyütme sıcaklığı, büyütme süresi, tavlama süresi, basınç, kullanılan alt-taş, kullanılan gazların saflıkları ve akış miktarları gibi birçok parametre etkilidir. Bu parametrelerden büyütme ve tavlama süreleri grafen sentezinde en önemli parametrelerdendir, bu nedenle bu çalışmada büyütme ve tavlama sürelerinin tek katmanlı homojen grafen sentezine olan etkisi araştırılmıştır. Farklı büyütme ve tavlama süreleri kullanılarak üretilen grafen filmler Raman Spektroskopisi tekniği kullanılarak karakterize edilmiş olup tek tabakalı homojen grafen sentezi için üretim süreci optimize edilmiştir. Genel anlamda tavlama sürelerinin 20 dakikadan 40 dakikaya kadar arttırıldığ gruplarında grafen kalitesinde ciddi bir değişim gözlenmemiştir. Büyütme sürelerinin arttırıldığı deney gruplarında ise 40 dakikaya kadar olan süre artışlarıyla doğru orantılı olarak grafen kalitesinin iyileştiği tespit edilmiştir.

Anahtar Kelimeler: Büyütme Süresi, CVD, Grafen, Metan Gazı, Raman Spektroskopisi, Tavlama Süresi

\section{Effect of the Annealing and Growth Time on Graphene Synthesis via Chemical Vapor Deposition Method}

\begin{abstract}
Due to its superior properties such as, has high conductivity, high durability and transparency, graphene is one of the most attractive material in recent years. The important parameters that affects graphene synthesis using chemical vapour deposition technique are growth temperature, growth time, annealing time, pressure, growth substrate, gas purity and gas flows. Among these parameters the growth time and annealing time are the most important parameters for graphene growth, thus in this study the effect of growth and annealing time on homogenous single layer graphene were investigated. The grown graphene films by using different growth and annealing time were characterized via Raman Spectroscopy technique and as a result single layer graphene growth process were optimized. In general, there was no significant change in the quality of the graphene in the experimental groups where the annealing time was increased from 20 minutes to 40 minutes. In the experimental groups where the growth time was increased, it was determined that the graphene quality improved with the time increases up to 40 minutes.
\end{abstract}

Key Words: Annealing Time, CVD, Graphene, Growth Time, Methane Gas, Raman Spectroscopy

\section{GİRISȘ (INTRODUCTION)}

Son zamanların en popüler araştırma konuları arasında yer alana grafen, bal peteği yapısına sahip olup yüksek iletkenlik, yüksek ışık geçirgenliği, yüksek dayanım ve esneklik gibi özelliklere sahip olmasından dolayı malzeme biliminde ilgi odağı haline gelmiştir (Ago ve diğ., 2012; Aïssa ve diğ., 2015). 
Bu üstün özelliklerinden dolayı grafen; transistörler, güneş hücreleri, yakıt pilleri, enerji depolama, bataryalar gibi birçok alanda kullanıma imkân sağlanmaktadır. Karbonun formlarından biri olan grafen fulleren, karbon nanotüp ve grafitin yapı taşını oluşturmaktadır (Geim ve Novoselov, 2007). Çevre dostu uygulamaların gelişmesine önemli derecede katkı sağlayan bu malzeme özellikle yenilenebilir enerji alanına önemli katkılar sağlayabilecektir (Bonaccorso ve diğ., 2015). Bu kapsamda grafen sentezi için araştırmacılar birçok yöntem üzerinde çalışmış ve daha kaliteli ve kolay grafen sentezi yöntemi için çalışmalarını sürdürmektedirler.

Grafen sentezi için mekanik ayrıştırma, kimyasal ayrıştırma, kimyasal buhar biriktirme (CVD) ve epitaksiyel büyütme gibi birçok yöntem kullanılabilmektedir. Mekanik ayrıştırma yöntemi ile tek katmanlı ve tek kristal yapıda kaliteli grafen filmler elde edilmesine karşın malzeme boyutu sınırlı kalmaktadır. Bu durum ayrıca, bu yöntemle sentezlenen grafenin uygulanabilme alanlarını kısıtlamakta ve endüstriyel üretim için uygun olmamaktadır. Bu anlamda grafenin geniş alanda tek katmanlı ve ince film olarak elde edilmesi ancak CVD yöntemi ile gerçekleştirilebilmektedir. Bu yöntem ile grafen sentezinin; kolay, hızlı, görece düşük maliyetli ve yaygın kullanım alanlarına sahip olması gibi birçok avantaj sağlamasına karşın sentez sürecinde her üretim parametresinin optimizasyonunun sağlanması ve kullanılan gaz ve alttaşların yüksek saflıkta olması gerekliliği bu yöntemin dezavantajları arasında ifade edilebilir (Li ve diğ., 2009; Liang ve diğ., 2011). CVD yöntemiyle sentezlenen grafenin; transistörler, sensörler, enerji depolama, güneş hücreleri gibi daha çok elektronik ve opto-elektronik uygulamaları bulunmaktadır. Bunun yanı sıra, kimyasal ayrıştırma (Hummers) yöntemi ile sentezlenen toz formundaki grafen/grafen oksit yapılar kompozitlerde, boya malzemelerinde, yüzey kaplamaları gibi endüstriyel uygulamalarda kullanılabilmektedir.

CVD yöntemi ile grafen sentezinde kullanılan gazların türü, saflığı ve akış oranları homojen ve kaliteli grafen sentezi için oldukça önemli faktörlerdendir (Li ve diğ., 2011). Ayrıca, homojen grafen sentezinde gaz parametrelerinin yanında sıcaklık, büyütme ve tavlama süreleri, kullanılan alt-taşlar gibi birçok parametre etkilidir. Tek parametre değişimi ile sentezlenen grafenin kalitesi etkilenebilmektedir. Çünkü farklı büyütme ve tavlama sürelerinde yapılan grafen sentezi işlemlerinde çok farklı grafen yapıları elde edildiği bilinmektedir (Mattevi ve diğ., 2011).

Metan gazının karbon kaynağı olarak kullanıldığı bu çalışmada, tek katlı homojen grafen sentezi için tavlama süreleri ve büyütme süreleri değiştirilerek bu parametrelerin grafen sentezine olan etkisi araştırılmış ve sentez süreci optimize edilmiştir. Karakterizasyon için temel olarak Raman spektroskopisi tekniği kullanılmıştır.

\section{MALZEME ve METOT (MATERIAL METHOD)}

\section{Malzeme (Material)}

Grafen sentezi için laboratuvarımız bünyesinde yer alan üç bölgeli ve altı gaz akış kanalına sahip CVD sistemi kullanılmıştır. CVD fırını içinde yer alan kuartz tüp $10 \mathrm{~cm}$ çapında ve toplam $85 \mathrm{~cm}$ büyüklüğünde olup, büyütmenin yapıldığı fırın bölgesi yaklaşık $25 \mathrm{~cm}$ boyundadır. Bu sistem kullanılarak yapılan büyütme işlemlerinde karbon kaynağı olarak \%99,9995 saflıkta Metan $\left(\mathrm{CH}_{4}\right)$ ve hidrojen kaynağı olarak \%99,9999 saflıkta Hidrojen $\left(\mathrm{H}_{2}\right)$ gazı kullanılmıştır. Çalışma kapsamında her adımda sadece tek parametre olmak üzere, tavlama ve büyütme süreleri değiştirilerek tek katmanlı homojen grafen sentezi gerçekleştirilmesi amaçlanmıştır. Grafen büyütme süresince kullanılan gazlar ve akış oranları, basınç, sıcaklık ve kullanılan alt-taş gibi sentezi etkileyen diğer tüm parametreler sabit tutulmuştur. Büyütme işlemlerinde daha önce tek katlı grafen sentezi için optimize edilen $30 \mathrm{sccm} \mathrm{CH}_{4}$ ve $20 \mathrm{sccm} \mathrm{H}_{2}$ gaz akış oranları bütün büyütme işlemlerinde sabit olarak kullanılmıştır. Grafen sentezi 25 $\mu \mathrm{m}$ kalınlıkta poli-kristal bakır folyo üzerinde gerçekleştirilmiş olup, büyüme öncesinde bu yüzeylere muhtemel kirlilikleri gidermek amacıyla IPA, saf su ve aseton ile temizleme işlemi uygulanmıştır. Daha sonra sentezlenen grafen tabakaları karakterizasyon amaciyla "wet transfer" adı verilen teknik kullanılarak $\mathrm{SiO}_{2} / \mathrm{Si}$ alt-taşlar üzerine transfer edilmiştir (Bae ve diğ., 2010). Raman spektroskopisi deneyleri $633 \mathrm{~nm}$ dalga boyuna sahip lazer kullanılarak gerçekleştirilmiştir. 


\section{Metot (Method)}

Şekil 1'de grafen sentezi için kullanılan süreç ve parametreleri içeren grafik verilmiştir. Bu grafik grafen sentez sürecini genel olarak ifade etmek için kullanılmıştır. Bu anlamda grafikte verilen, 1sıtma, tavlama, büyütme ve soğutma süreleri ile gaz akış oranları yapılan her deney grubu için ayrı belirlenmiştir. Bu çalışma kapsamında ısıtma ve soğutma süreleri, gaz akış oranları ve basınç değerleri yapılan tüm deneylerde sabit tutulmuş olup bu sabit değerler için literatürden ve önceki çalışmalarımızdan yararlanılmıştır (Choi ve diğ., 2010; Mattevi ve diğ., 2011). Yapılan deneylerle tavlama ve büyütme sürelerinin değişiminin grafen sentezine olan etkisi araştırılmıştır. Bu amaç doğrultusunda her deney grubunda öncelikle tavlama süresi (20, 30 ve 40 dakika) sabit tutularak büyütme süreleri $(15,20,25,30,35,40$ dakika) değiştirilmiştir.

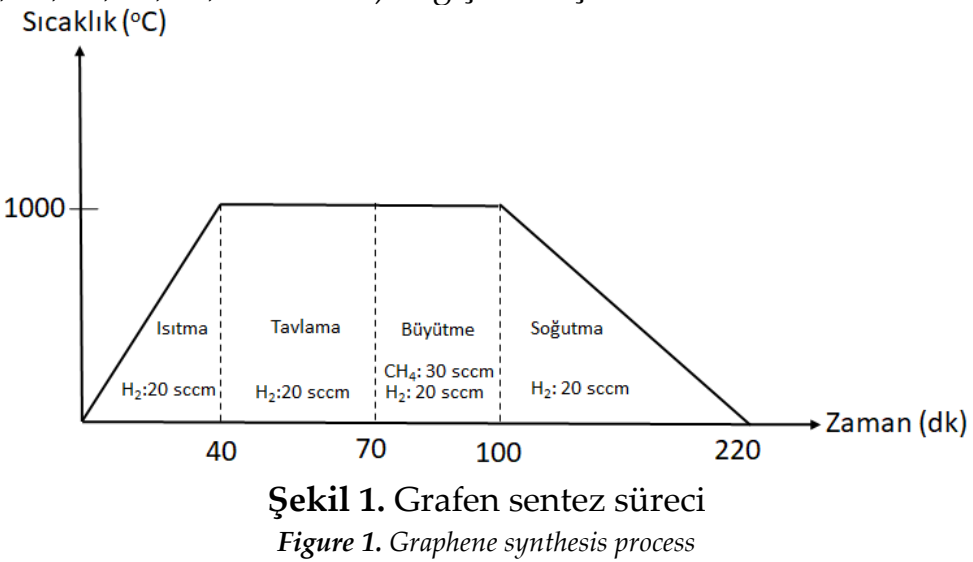

Çizelge 1'de belirtildiği gibi tavlama süresi (annealing time) başlangıçta 20 dakika sabit kalacak şekilde büyütme süresi (growth time) 15 dakikadan 40 dakika ya kadar 5'er dakika arttırılarak bakır üzerinde grafen sentezi gerçekleştirilmiştir. Daha sonra aynı işlem tavlama süresi 30 dakika ve 40 dakika olacak şekilde ve diğer parametreler önceki işlemlerle aynı kalacak şekilde uygulanarak büyütme süresi ve tavlama süresinin grafen sentezine etkisi araştırılmış ve sentez sürecinin optimizasyonu gerçekleştirilmiştir. Büyütme sıcaklığı tüm deneyler için $1000{ }^{\circ} \mathrm{C}^{\prime}$ de sabit tutulmuş olup büyütme işlemleri $10^{-1}$ torr vakumda gerçekleştirilmiştir. Bu basınç değeri CVD sistemine bağlı vakum pompasının varabildiği en iyi değer olduğundan kullanılmıştır, aksi durumda daha yüksek ve daha düşük basınç koşullarında da farklı sentez parametreleri kullanılarak grafen sentezi gerçekleştirilebilmektedir.

Çizelge 1. Tek katlı grafen sentezi için tavlama süresi ve büyütme süresi optimizasyonu Table 1. Optimized annealing and growth time for single layer graphene growth

\begin{tabular}{|c|c|c|c|c|}
\hline $\left.\mathbf{H}_{\mathbf{2}} \mathbf{( s c c m}\right)$ & $\left.\mathbf{C H}_{\mathbf{4}} \mathbf{( s c c m}\right)$ & Isitma (dk) & Tavlama (dk) & Büyütme (dk) \\
\hline 20 & 30 & 40 & $20(30-40)$ & 15 \\
\hline 20 & 30 & 40 & $20(30-40)$ & 20 \\
\hline 20 & 30 & 40 & $20(30-40)$ & 25 \\
\hline 20 & 30 & 40 & $20(30-40)$ & 30 \\
\hline 20 & 30 & 40 & $20(30-40)$ & 35 \\
\hline 20 & 30 & 40 & $20(30-40)$ & 40 \\
\hline
\end{tabular}

Sentezlenen grafen filmlerin karakterizasyonu için temel olarak Raman spektroskopisi tekniği kullanılmış olup, ölçümler $633 \mathrm{~nm}$ dalga boyuna sahip lazer kullanılarak gerçekleştirilmiştir. Yapılan deneysel ölçümlerde Raman spektrumları ve Raman haritaları elde edilmiştir. Grafene ait Raman spektrumlarında sırasıyla D, G, 2D olarak adlandırılan pikler ortaya çıkmaktadır ve bu pikler grafene ait kusurlar, film kalınlıkları ve film kalitesi hakkında bilgiler sağlamaktadırlar (Ferrari ve diğ., 2006; Li ve diğ., 2009). D piki olarak adlandırılan pik grafen kusurlarını belirlemek amacıyla kullanılmaktadır. 2D 
ve $G$ pikleri ise literatürde birbirlerine oranlanarak tek katlı ya da çok katlı grafen katmanı belirlenmesinde kullanılmaktadır aynı zamanda 2D pikinin pozisyonu da bu konu hakkında bilgi vermektedir. Grafen kalitesini belirlemede diğer önemli parametreler grafene ait I2D/IG oranı, 2D piki için FWHM (maksimum yarı tam genişlik) ve piklerin bulunduğu merkezlerdir. Tek katmanlı grafene ait FWHM değeri literatürde ortalama $27,5 \pm 3,8 \mathrm{~cm}^{-1}$ olarak belirlenmiş ve tek katmandan 3 katmana kadar I2D/IG oranı için bu değer 1,29 1,55 arasında belirlenmiştir. Grafen katman sayısının artış1 ile FWHM'nin arttığı bilindiğinden, katman sayısının belirlenmesinde kullanılan etkin bir parametredir (Hao ve diğ., 2010; Capasso ve diğ., 2015).

\section{BULGULAR VE TARTIŞMA (RESULTS and DISCUSSION)}

\section{Tavlama Süresinin 20 Dakika Sabit Tutulup Büyütme Süresinin 15 Dakikadan 40 Dakikaya Kadar}

Değişimi ile Grafen Sentezi (Graphene Synthesis with Annealing Time Constant for 20 Minutes and a Change in the Magnification Time from 15 Minutes to 40 Minutes.)

Tavlama süresinin 20 dakika tutulup, büyütme süresinin 15 dakikadan 40 dakikaya kadar 5'er dakikalık zaman aralıklarıyla arttırılarak elde edilen numunelerin (6 adet) karakterizasyonu sonrasında elde edilen sonuçlarda tüm büyütme işlemlerinde grafen sentezi başarılı bir şekilde gerçekleştirildiği anlaşılmıştır. Ancak, tavlama süresinin 20 dakika, büyütme süresinin 35 dakika olduğu numunelerde tek katlı ve homojen grafen sentezinin daha başarılı bir şekilde gerçekleştiği Şekil 2'de verilen Raman spektroskopisi grafiğinden ve Raman haritalarından anlaşılmaktadır. Her ne kadar diğer parametrelerin (sürelerin) kullanımı ile grafen sentezi gerçekleştirilebilmiş olsa da tek tabakalı ve homojen grafen sentezi mümkün olmamıştır. Raman spektrumlarından grafen sentezinde büyütme süresinin 15 dakikadan 35 dakikaya kadar 5'er dakikalık adımlarla arttırılması ile grafen kalitesinin doğru orantılı olarak arttığı ve sonrasında kalitenin düştüğü gözlenmiştir. Tüm bu verilen bilgilerden yola çıkarak Çizelge 2' de gösterildiği gibi tavlama süresinin 20 dakika büyütme süresinin 35 dakika olduğu durumda FWHM değeri $23 \mathrm{~cm}^{-1}$ ve I2D/IG oranı 3,95 olarak belirlenmiştir.

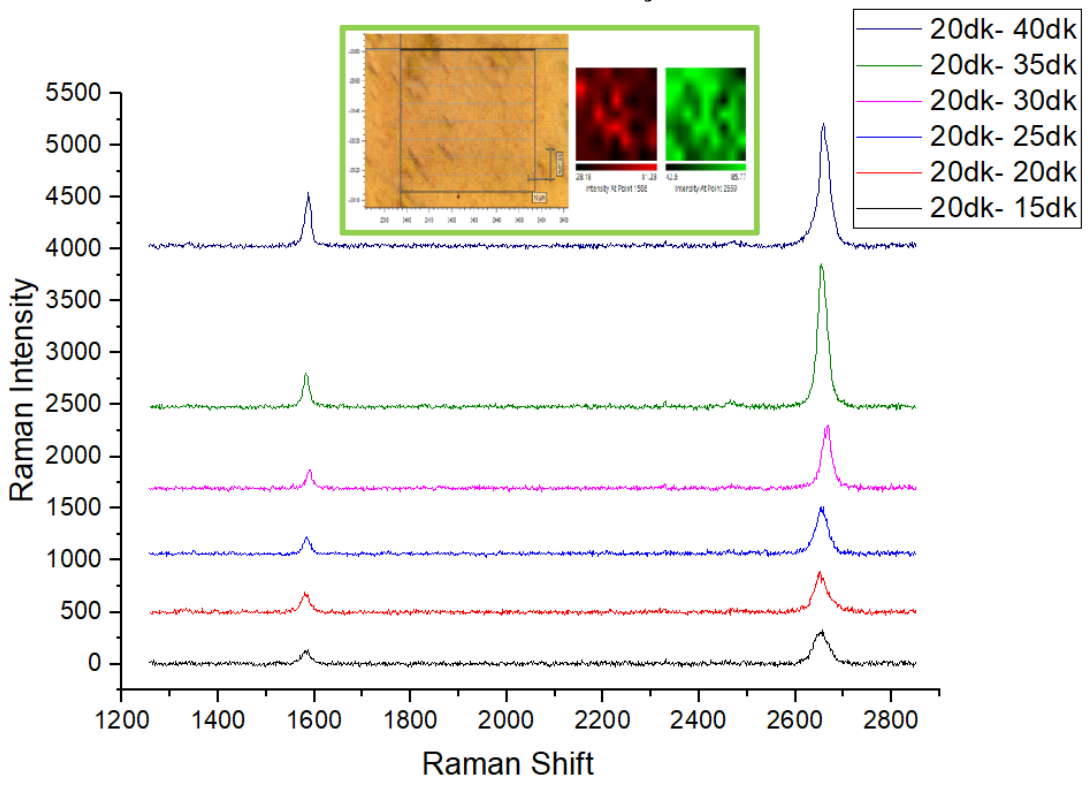

Şekil 2. Tavlama süresinin 20 dakika sabit tutulup büyütme süresinin 15 dakikadan 40 dakikaya kadar değiştirilerek sentezlenen grafenin Raman spektroskopisi sonuçları. Grafiğin içinde yer alan yeşil dikdörtgen içinde haritalama yapılan bölgenin optik mikroskop görüntüsü (sarı renkli) ve en iyi grafen tabakasına ait Raman haritalarını (G ve 2D pikleri) içermektedir.

Figure 2. Annealing time was kept $20 \mathrm{~min}$. constantly and growth time was changed from $15 \mathrm{~min}$. to $40 \mathrm{~min}$. and these figure represents to Raman spectroscopy results according to these parameters. 
Çizelge 2. 20 dakika tavlanan grafen filmlerine ait $\mathrm{I}_{2 \mathrm{D}}$, $\mathrm{I}_{2 \mathrm{D}} / \mathrm{IG}_{\mathrm{G}}$ ve FWHM değerleri

Table 2. $I_{2 D}, I_{2 D} / I_{G} v e$ FWHM values of annealed graphene films for 20 mins.

\begin{tabular}{|c|c|c|c|c|c|}
\hline Deneyler & $\begin{array}{c}\text { Tavlama } \\
\text { Süresi }\end{array}$ & $\begin{array}{c}\text { Büyütme } \\
\text { Süresi }\end{array}$ & $\begin{array}{c}\text { Pik } \\
\text { Pozisyonu }\end{array}$ & $\mathbf{I}_{2 \mathrm{D}} / \mathbf{I}_{\mathbf{G}}$ & FWHM \\
\hline A1 & 20 & 15 & $2653 \mathrm{~cm}^{-1}$ & 2,5 & $39 \mathrm{~cm}^{-1}$ \\
\hline A2 & 20 & 20 & $2652 \mathrm{~cm}^{-1}$ & 2,37 & $30 \mathrm{~cm}^{-1}$ \\
\hline A3 & 20 & 25 & $2653 \mathrm{~cm}^{-1}$ & 2,69 & $30 \mathrm{~cm}^{-1}$ \\
\hline A4 & 20 & 30 & $2664 \mathrm{~cm}^{-1}$ & 3,32 & $26 \mathrm{~cm}^{-1}$ \\
\hline A5 & 20 & 35 & $2653 \mathrm{~cm}^{-1}$ & 3,95 & $23 \mathrm{~cm}^{-1}$ \\
\hline A6 & 20 & 40 & $2657 \mathrm{~cm}^{-1}$ & 2,23 & $26 \mathrm{~cm}^{-1}$ \\
\hline
\end{tabular}

Tavlama Süresinin 30 Dakika Sabit Tutulup Büyütme Süresinin 15 Dakikadan 40 Dakikaya Kadar Değişimi ile Grafen Sentezi (Graphene Synthesis with Annealing Tİme Constant for 30 Minutes and a Change in the Magnification Time from 15 Minutes to 40 Minutes.)

Bir sonraki araştırmamızda tavlama süresi 30 dakika olarak belirlenmiş (sabit) ve büyütme süresi ise yine 15 dakikadan 40 dakikaya kadar değiştirilmiştir. Şekil 3'de Raman spektroskopisine ait sonuçlar incelendiğinde burada tavlama süresi 30 dakika ve 40 dakikalık büyütme süresi ile gerçekleştirilen grafen sentezinin daha başarılı sonuçlar verdiği gözlenmiştir. Bu parametrelerle sentezlenen grafen tabakasının homojenliği ayrıca Şekil 3'te verilen Raman haritalarından da anlaşılmaktadır. Bunun yanı sıra Çizelge $3^{\prime}$ te verildiği gibi I2D/IG oranı tavlama süresi 30 dakika ve büyütme süresi 40 dakika olan çalışma için 3,76 FWHM değeri ise $26 \mathrm{~cm}^{-1}$ olarak belirlenmiştir ve belirtilen parametreler için başarılı bir şekilde tek katlı ve homojen grafen sentezi gerçekleştirilmiştir. Diğer büyütme parametreleri incelendiğinde ise 40 dakikaya kadar olan büyütme adımlarında değerlerin iyileştiği görülmektedir sonraki süreler için sentezlenen grafenin kalitesinde değişme olmadığı gözlenmiştir. Bu amaç doğrultusunda 30 dakika tavlama süresine karşın 45 ve 50 dakika büyütme sürelerinde elde edilen grafen tabakalarının kalitesinin etkilenmediği belirlenmiştir.

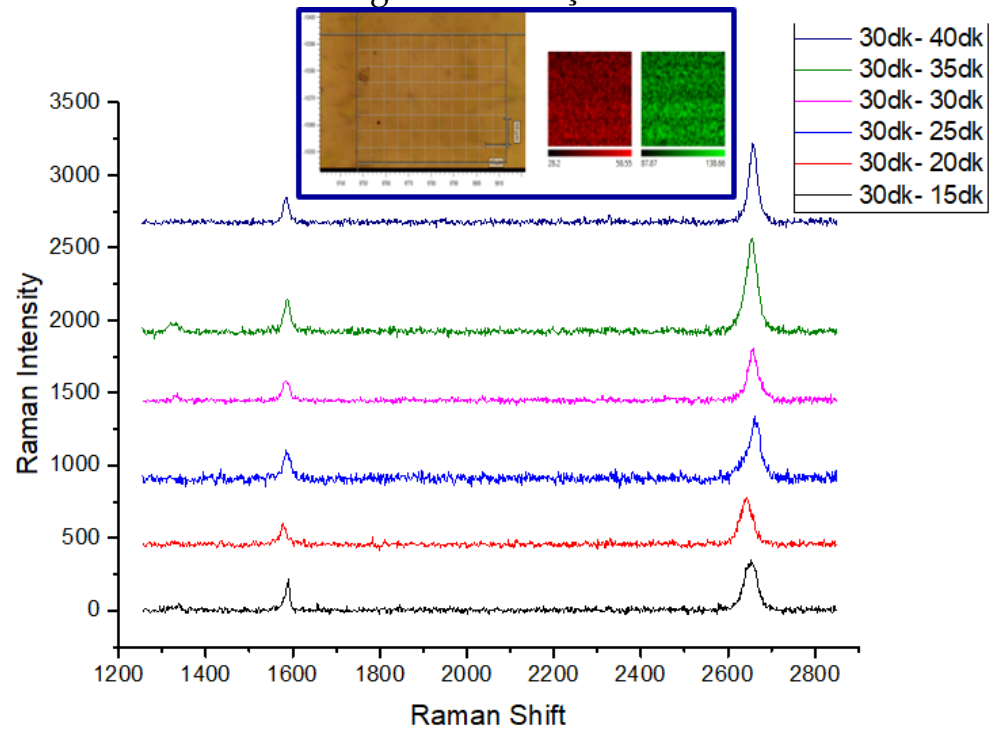

Şekil 3. Tavlama süresinin $30 \mathrm{dk}$ sabit tutulup büyütme süresinin $15 \mathrm{dk}$ 'dan $40 \mathrm{dk}$ ya kadar değiştirilerek sentezlenen grafenin Raman spektroskopisi sonuçları. Grafiğin içinde yer alan mavi dikdörtgen içinde haritalama yapılan bölgenin optik mikroskop görüntüsü (sarı renkli) ve en iyi grafen tabakasına ait Raman haritalarını (G ve 2D pikleri) içermektedir

Figure 3. Annealing time was kept $30 \mathrm{~min}$. constantly and growth time was changed from $15 \mathrm{~min}$. to 40 min. and these figure represents to Raman spectroscopy results according to these parameters. Blue rectangular inside the graph shows optical image of the area where the maps were taken and the best graphene Raman maps ( $G$ and $2 D$ ) 
Çizelge 3. 30 dakika tavlanan grafen filmlere ait I2D, I2D/IG ve FWHM değerleri Table 3. I2D, I2D/IG ve FWHM values of annealed graphene films for 30 mins.

\begin{tabular}{|c|c|c|c|c|c|}
\hline Deneyler & $\begin{array}{c}\text { Tavlama } \\
\text { Süresi }\end{array}$ & $\begin{array}{c}\text { Büyütme } \\
\text { Süresi }\end{array}$ & $\begin{array}{c}\text { Pik } \\
\text { Pozisyonu }\end{array}$ & I2D/ IG & FWHM \\
\hline B1 & 30 & 15 & $2654 \mathrm{~cm}^{-1}$ & 1,43 & $22 \mathrm{~cm}^{-1}$ \\
\hline B2 & 30 & 20 & $2643 \mathrm{~cm}^{-1}$ & 2,91 & $34 \mathrm{~cm}^{-1}$ \\
\hline B3 & 30 & 25 & $2662 \mathrm{~cm}^{-1}$ & 3,03 & $35 \mathrm{~cm}^{-1}$ \\
\hline B4 & 30 & 30 & $2657 \mathrm{~cm}^{-1}$ & 3,55 & $28 \mathrm{~cm}^{-1}$ \\
\hline B5 & 30 & 35 & $2654 \mathrm{~cm}^{-1}$ & 3,89 & $26 \mathrm{~cm}^{-1}$ \\
\hline B6 & 30 & 40 & $2656 \mathrm{~cm}^{-1}$ & 3,76 & $26 \mathrm{~cm}^{-1}$ \\
\hline
\end{tabular}

Tavlama Süresinin 40 Dakika Sabit Tutulup Büyütme Süresinin 15 Dakikadan 40 Dakikaya Kadar Değişimi ile Grafen Sentezi (Graphene Synthesis with Constant Annealing Time for 40 Minutes and Change of Time from 15 Minutes to 40 Minutes)

Bu adımda da büyütme süreleri önceki çalışmalara benzer olacak şekilde 15 dakikadan 40 dakikaya kadar değiştirilmiştir. Şekil 4'de her bir adım için verilen Raman spektroskopisi grafiklerinden de görüldüğü gibi 40 dakikalık tavlama ve 30 dakikalık büyütme süresi ile gerçekleştirilen grafen sentezinin daha başarılı sonuçlar verdiği gözlenmiştir. Homojen tek tabakalı grafen sentezine ilişkin bu gözlem ayrıca Şekil 4'te verilen Raman haritalarından da görülebilmektedir.

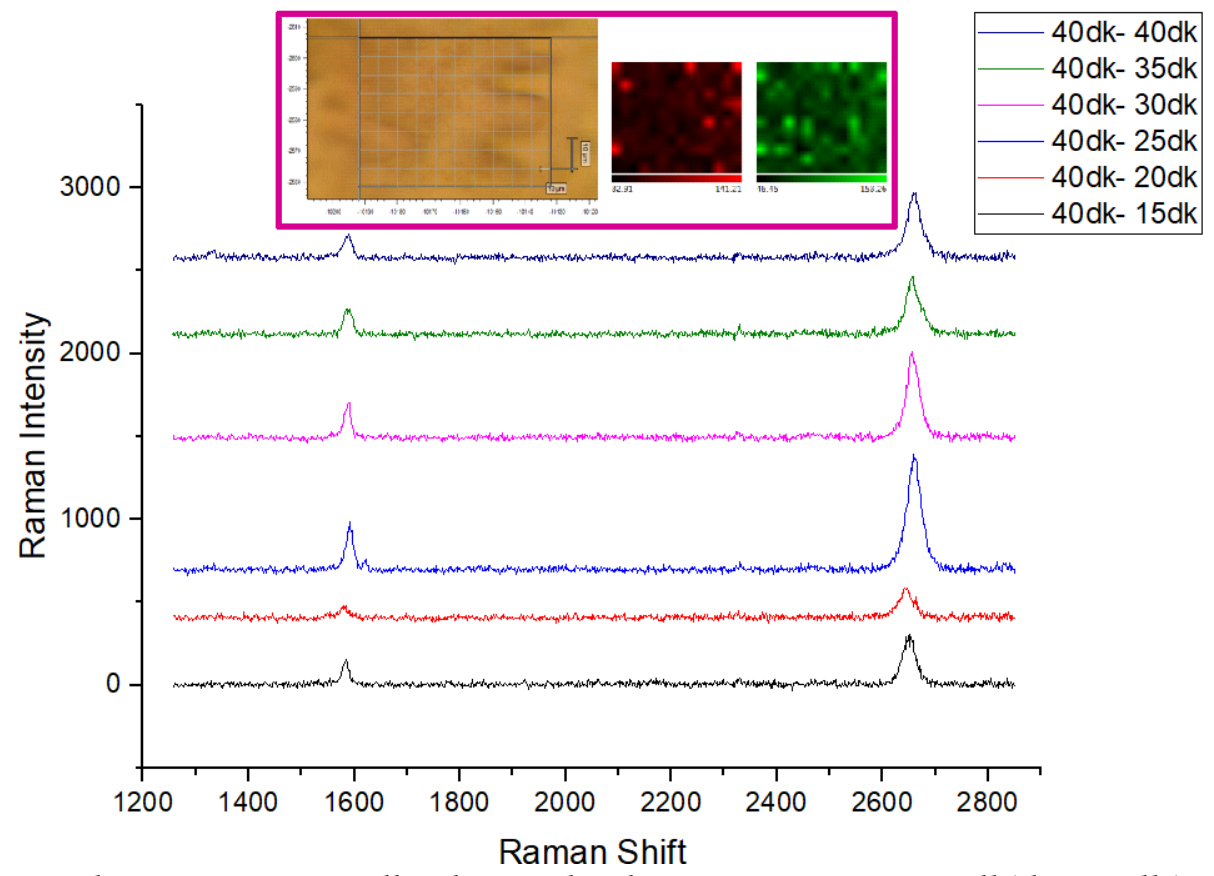

Şekil 4. Tavlama süresinin $40 \mathrm{dk}$ sabit tutulup büyütme süresinin $15 \mathrm{dk}$ 'dan $40 \mathrm{dk}$ 'ya kadar değiştirilerek sentezlenen grafenin Raman spektroskopisi sonuçları. Grafiğin içinde yer alan pembe dikdörtgen içinde haritalama yapılan bölgenin optik mikroskop görüntüsü (sarı renkli) ve en iyi grafen tabakasına ait Raman haritalarını (G ve 2D pikleri) içermektedir

Figure 4. Annealing time was kept $40 \mathrm{~min}$. constantly and growth time was changed from $15 \mathrm{~min}$. to $40 \mathrm{~min}$. and these figure represents to Raman spectroscopy results according to these parameters. Pink rectangular inside the graph shows optical image of the area where the maps were taken and the best graphene Raman maps ( $G$ and $2 D$ )

Daha önce verilen bilgilerden yola çıkarak Çizelge 4'de verilen değerler incelendiğinde bu adımda gerçekleşen en iyi değerin, $\mathrm{I}_{2 \mathrm{D}} / \mathrm{I}_{\mathrm{G}}=2,63$ ve $\mathrm{FWHM}=30 \mathrm{~cm}^{-1}$ değerine sahip 40 dakikalık tavlama 30 dakikalık büyütme işlemine ait olduğu görülmektedir. Tavlama süresinin 40 dakika olarak sabit tutulduğu bu adımda büyütme sürelerinin değiştirilmesiyle birbirinden çok farklı sonuçlara 
rastlanmamıştır genellikle her bir deney adımı için çok katmanlı grafen tabakasına rastlanmıştır. Yapılan bu deney grubu diğer deney grupları ile karşılaştırıldığında homojen yapıya daha az rastlanmıştır.

Çizelge 4. 40 dakika tavlanan grafen filmlere ait I2D, I2D/ IG ve FWHM değerleri Table 4. I $I_{2 D} I_{2 D} / I_{G}$ ve FWHM values of annealed graphene films for 40 mins.

\begin{tabular}{|c|c|c|c|c|c|}
\hline Deneyler & $\begin{array}{c}\text { Tavlama } \\
\text { Süresi }\end{array}$ & $\begin{array}{c}\text { Büyütme } \\
\text { Süresi }\end{array}$ & $\begin{array}{c}\text { Pik } \\
\text { Pozisyonu }\end{array}$ & $\mathbf{I}_{2 \mathrm{D}} / \mathbf{I}_{\mathbf{G}}$ & FWHM \\
\hline $\mathrm{C} 1$ & 40 & 15 & $2647 \mathrm{~cm}^{-1}$ & 2,16 & $33 \mathrm{~cm}^{-1}$ \\
\hline $\mathrm{C} 2$ & 40 & 20 & $2643 \mathrm{~cm}^{-1}$ & 2,42 & $39 \mathrm{~cm}^{-1}$ \\
\hline $\mathrm{C} 3$ & 40 & 25 & $2659 \mathrm{~cm}^{-1}$ & 2,38 & $36 \mathrm{~cm}^{-1}$ \\
\hline $\mathrm{C} 4$ & 40 & 30 & $2655 \mathrm{~cm}^{-1}$ & 2,63 & $30 \mathrm{~cm}^{-1}$ \\
\hline C5 & 40 & 35 & $2655 \mathrm{~cm}^{-1}$ & 2,21 & $34 \mathrm{~cm}^{-1}$ \\
\hline C6 & 40 & 40 & $2658 \mathrm{~cm}^{-1}$ & 2,42 & $31 \mathrm{~cm}^{-1}$ \\
\hline
\end{tabular}

\section{SONUÇLAR (RESULTS)}

Yapılan tüm çalışmalar sonucunda deney grupları içerisinde en iyi sonuçlara ait parametreler belirlenip kendi aralarında karşılaştııılmıştır. Şekil 2, Şekil 3 ve Şekil 4'de verilen Raman sonuçları doğrultusunda her bir deney grubu içerisinde en başarılı sonucu veren deneyler karşılaştırılmıştır. Bu anlamda 20 dakika, 30 dakika ve 40 dakikalık tavlama süreleri ile büyütme sürelerinin 15 dakikadan 40 dakikaya kadar değiştirlerek yapılan deneyler sonucunda elde edilen en iyi sonuçlara ait Raman spektrumları Şekil 5'de gösterilmiştir ve Çizelge 5'de ise bu deneylere ait parametrelere yer verilmiştir. 20 dakikalık tavlama süresine ait en iyi büyütme süresi 35 dakika, 30 dakikalık tavlama süresine ait en iyi büyütme süresi 40 dakika ve 40 dakikalık tavlama süresine ait en iyi büyütme süresi 30 dakika olarak belirlenmiştir. 40 dakikalık büyütme süresi kullanılarak bakır yüzey üzerinde sentezlenen grafen tek katmanlı olarak üretilebilmesine karşın filmin homojenliği diğer büyütme sürelerine kıyaslandığında daha düşük kalmaktadır. Büyütme süresinin genellikle karbon çözünürlülügü̈nün daha yüksek olduğu nikel yüzey üzerinde yapılan büyütmelerde etkili olduğu ve süre artışı ile birlikte çok katmanlı filmler elde edildiği bilinmektedir (Chae ve diğ., 2009; Wu ve diğ., 2016).

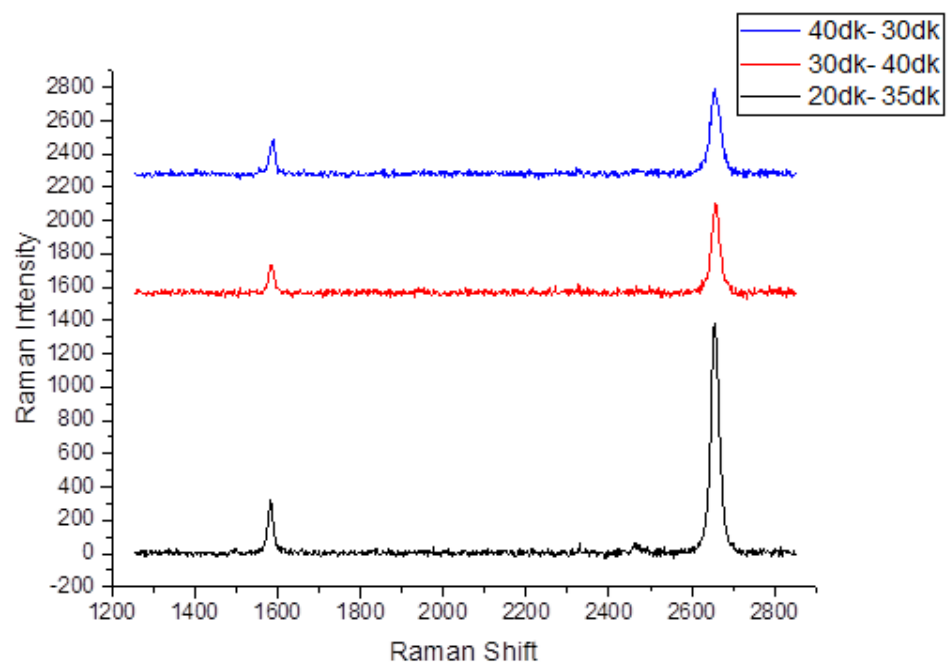

Şekil 5. Yapılan çalışmalarda sentezlenen en iyi grafen filmlerin Raman spektroskopisi sonuçları Figure 5. Raman spectroscopy results of the best graphene layer 
Çizelge 5. Yapılan deneyler sonucunda en iyi büyütmenin elde edildiği parametreler Table 5. As a result of the experiments performed, the parameters obtained by the best synthesis

\begin{tabular}{|c|c|c|c|c|c|}
\hline Deneyler & $\mathbf{H}_{\mathbf{2}} \mathbf{( s c c m )}$ & $\left.\mathbf{C H}_{\mathbf{4}} \mathbf{( s c c m}\right)$ & Isitma (dk) & Tavlama (dk) & Büyütme (dk) \\
\hline A5 & 20 & 30 & 40 & 20 & 35 \\
\hline B6 & 20 & 30 & 40 & 30 & 40 \\
\hline C4 & 20 & 30 & 40 & 40 & 30 \\
\hline
\end{tabular}

Yapılan grafen sentez deneyleri sonucuna göre sabit tavlama süreleri için büyütme sürelerinin genel olarak 30 dakikadan 40 dakikaya kadar daha başarılı sonuçlar ortaya koyduğu gözlemlenmiştir. Tavlama ve büyütme süreleri ile yapılan önceki çalışmalara bakıldığında optimum tavlama sürelerinin polikristal bakır yüzeylerdeki tanecik sınırlarını arttırdığı ve böylece grafen kalitesini arttırdığı gözlenmiştir. Ayrıca, büyütme sürelerinin artışı ile de grafen kalitesinin arttı̆̆ bilinmektedir (Choi ve diğ., 2010; Mattevi ve diğ., 2011). Grafen kalitesine sentez sürecinde bir çok parametre eş zamanlı olarak etki edebileceğinden dolayı aynı parametreler ile gerçekleşen çalışmalarla kıyaslama yapmak daha doğru yorum yapılmasına katkı sağlayacaktır.

Çizelge 6'da bu deney gruplarına ait en iyi sonuçların I2D, I2D/ IG ve FWHM değerleri gösterilmiştir. Tüm bu değerler karşılaştırıldığında ise bu gruplar arasında en iyi sonucun 20 dakika tavlama, 35 dakika büyütme sürelerinde sentezlenen grafenin daha başarılı olduğunu göstermiştir. Ayrıca bu parametrelerde sentezlenen grafen için; I $\mathrm{I}_{2 \mathrm{D}}=2653 \mathrm{~cm}^{-1}$, I $\mathrm{I}_{\mathrm{D}} / \mathrm{I}_{\mathrm{G}}=3,95 \mathrm{FWHM}=23 \mathrm{~cm}^{-1}$ olarak belirlenmiştir. Bu sonuçların, yapılan deneyler kapsamında en iyi değerler olduğu anlaşılmıştır. Bu kapsamda, 20 dakikalık tavlama, 35 dakikalık büyütme süresi ile yapılan çalışmalar sonucunda homojen tek tabakalı grafen elde edildiğinden dolayı bu parametrelerde grafen sentezi için öne çıkmaktadır.

Çizelge 6. Yapılan deneyler sonucunda en iyi grafen filmlere ait I2D, I2D/ IG ve FWHM değerleri Table 6. Best $I_{2 D}, I_{2 D} / I_{G}$ ve FWHM results according to experiments

\begin{tabular}{|c|c|c|c|c|}
\hline $\begin{array}{c}\text { Tavlama } \\
\text { Süresi }\end{array}$ & $\begin{array}{c}\text { Büyütme } \\
\text { Süresi }\end{array}$ & $\begin{array}{c}\text { Pik } \\
\text { Pozisyonu }\end{array}$ & I2D/ IG & FWHM \\
\hline 20 & 35 & $2653 \mathrm{~cm}^{-1}$ & 3,95 & $23 \mathrm{~cm}^{-1}$ \\
\hline 30 & 40 & $2656 \mathrm{~cm}^{-1}$ & 3,76 & $26 \mathrm{~cm}^{-1}$ \\
\hline 40 & 30 & $2655 \mathrm{~cm}^{-1}$ & 2,63 & $30 \mathrm{~cm}^{-1}$ \\
\hline
\end{tabular}

\section{TEŞEKKÜR (ACKNOWLEDGEMENT)}

Bu çalışma TÜBİTAK tarafından 117M401 nolu proje ile desteklenmiştir.

\section{KAYNAKLAR (REFERENCES)}

Ago, H., Ogawa, Y., Tsuji, M., Mizuno, S. ve Hibino, H., 2012, Catalytic growth of graphene: toward large-area single-crystalline graphene, The journal of physical chemistry letters, 3 (16), 2228-2236.

Aïssa, B., Memon, N. K., Ali, A. ve Khraisheh, M. K., 2015, Recent progress in the growth and applications of graphene as a smart material: A review, Frontiers in Materials, 2, 58.

Bae, S., Kim, H., Lee, Y., Xu, X., Park, J.-S., Zheng, Y., Balakrishnan, J., Lei, T., Kim, H. R. ve Song, Y. I., 2010, Roll-to-roll production of 30-inch graphene films for transparent electrodes, Nature nanotechnology, 5 (8), 574.

Bonaccorso, F., Colombo, L., Yu, G., Stoller, M., Tozzini, V., Ferrari, A. C., Ruoff, R. S. ve Pellegrini, V., 2015, Graphene, related two-dimensional crystals, and hybrid systems for energy conversion and storage, Science, 347 (6217), 1246501.

Capasso, A., Dikonimos, T., Sarto, F., Tamburrano, A., De Bellis, G., Sarto, M. S., Faggio, G., Malara, A., Messina, G. ve Lisi, N., 2015, Nitrogen-doped graphene films from chemical vapor deposition of pyridine: influence of process parameters on the electrical and optical properties, Beilstein journal of nanotechnology, 6, 2028. 
Chae, S. J., Güneş, F., Kim, K. K., Kim, E. S., Han, G. H., Kim, S. M., Shin, H. J., Yoon, S. M., Choi, J. Y. ve Park, M. H., 2009, Synthesis of large-area graphene layers on poly-nickel substrate by chemical vapor deposition: wrinkle formation, Advanced Materials, 21 (22), 2328-2333.

Choi, W., Lahiri, I., Seelaboyina, R. ve Kang, Y. S., 2010, Synthesis of graphene and its applications: a review, Critical Reviews in Solid State and Materials Sciences, 35 (1), 52-71.

Ferrari, A. C., Meyer, J., Scardaci, V., Casiraghi, C., Lazzeri, M., Mauri, F., Piscanec, S., Jiang, D., Novoselov, K. ve Roth, S., 2006, Raman spectrum of graphene and graphene layers, Physical review letters, 97 (18), 187401.

Geim, A. K. ve Novoselov, K. S., 2007, The rise of graphene, Nature materials, 6 (3), 183.

Hao, Y., Wang, Y., Wang, L., Ni, Z., Wang, Z., Wang, R., Koo, C. K., Shen, Z. ve Thong, J. T., 2010, Probing layer number and stacking order of few-layer graphene by Raman spectroscopy, small, 6 (2), 195-200.

Li, X., Cai, W., An, J., Kim, S., Nah, J., Yang, D., Piner, R., Velamakanni, A., Jung, I. ve Tutuc, E., 2009, Large-area synthesis of high-quality and uniform graphene films on copper foils, Science, 324 (5932), 1312-1314.

Li, Z., Wu, P., Wang, C., Fan, X., Zhang, W., Zhai, X., Zeng, C., Li, Z., Yang, J. ve Hou, J., 2011, Lowtemperature growth of graphene by chemical vapor deposition using solid and liquid carbon sources, ACS nano, 5 (4), 3385-3390.

Liang, X., Sperling, B. A., Calizo, I., Cheng, G., Hacker, C. A., Zhang, Q., Obeng, Y., Yan, K., Peng, H. ve Li, Q., 2011, Toward clean and crackless transfer of graphene, ACS nano, 5 (11), 9144-9153.

Mattevi, C., Kim, H. ve Chhowalla, M., 2011, A review of chemical vapour deposition of graphene on copper, Journal of Materials Chemistry, 21 (10), 3324-3334.

Wu, X., Zhong, G., D'arsié, L., Sugime, H., Esconjauregui, S., Robertson, A. W. ve Robertson, J., 2016, Growth of continuous monolayer graphene with millimeter-sized domains using industrially safe conditions, Scientific reports, 6, 21152. 